\title{
CREATIVE EXCHANGE: AN EVOLVING MODEL OF MULTIDISCIPLINARY COLLABORATION
}

\author{
Katja Fleischmann \\ School of Creative Arts \\ James Cook University, Australia \\ katja.fleischmann@jcu.edu.au \\ Clive Hutchison \\ School of Creative Arts \\ James Cook University, Australia \\ clive.hutchison@jcu.edu.au
}

\begin{abstract}
Often the traditional creative arts curriculum does not sufficiently respond to, nor reflect, contemporary work practice. Multidisciplinary teams are now increasingly the norm in creative arts practice especially when driven by technological innovation. Drawing on contemporary research that centres on the benefits of multidisciplinary collaboration, Creative Exchange is a direct attempt to implement multidisciplinary practice within a tertiary learning environment. Outcomes aim to prepare students for dynamic engagement with the challenges and possibilities of their future workplace in the creative arts industries. After the initial planning stages and based on recent research findings, the scope of Creative Exchange has broadened from collaborative engagement within the creative arts to a broader rationale that includes noncreative arts' disciplines e.g. Information Technology, Business and Journalism. In order to develop a sustainable solution this approach was formalised in the POOL MODEL framework (Fleischmann, 2008a, 2008b, 2010) within which Creative Exchange saw its first implementation in 2009 in the School of Creative Arts at James Cook University.
\end{abstract}

\section{Keywords}

design education, creative arts curriculum, multidisciplinary collaboration, learning and teaching pool, curriculum design

\section{The background to Creative Exchange}

The traditional university-based creative arts curriculum often has not sufficiently responded to, nor reflected, contemporary workplace realities. This was significantly the case at the authors' University's school. However, recent sweeping changes have seen a complete restructure of the School of Creative Arts with a reinvention of the curriculum. Integral to these changes have been the interrogation and evolution of new possibilities that aim to position future students not only at the centre of new media arts practice, but as versatile and adaptable professionals prepared to seek strategic alliances, within and external to, the creative arts.

Creative arts professionals within a range of creative industries - including advertising, animation, video and film production, performing arts, and entertainment - have long structured their workplace relationships around a variety of team-based models. In advertising, for example, at the 
core of the creative team are the designer and the copywriter. Team members draw on the depth of their discipline-specific expertise in order to achieve a desired shared outcome. As the concept takes form and its production progressively gains realisation, others are solicited to the team, each adding to, shaping, and advancing the project. These might be photographers, visualisers, typographers, or 3D modelers, the team evolving organically towards eventual completion of the project.

Increasingly, these types of multidisciplinary teams are now the norm in creative arts practice, especially when driven by technological innovation. Whereas in some areas, such as animation, even from their earliest days, they have always required close collaboration between artists and scientists, poets and engineers (Ebert \& Bailey, 1999), other more traditionally "underground" (i.e. not in the spotlight) creative pursuits, such as design and photography, are increasingly looking beyond the scope of their disciplines in a search for new alignments and partnerships which will facilitate new technologies and online opportunities. More recently, in professional practice, intersections between Information Technology (IT) and the creative arts have flourished, especially since the advent of Web 2.0 applications, new games development and a proliferation of technologically driven art-based projects. The cast of players includes designers, robotics and software engineers, researchers and theorists, but it might also incorporate digital photographers, illustrators, 3D model makers, musical composers, performers and more. The scope of this intersection is well known: Nowadays software, electronics, mathematics, robotic technology, genetic art, algorithmic art, led installations, and artificial intelligence in union with music, dance, sculpture and painting expression are used to involve the audience as part of an interactive dialogue with technology (Ahmed et al., 2009).

However, new participants in these multidisciplinary teamwork-based models, especially those direct from tertiary education, are often unprepared for the rigours and challenges of managing these relationships, their educational experience having supplied them with little empathy for, or understanding of, these other professionals with whom they will now need to work so closely (DiPaola, Dorosh \& Brandt, 2004; Heller, 2005). They are also often unfamiliar with the machinations of team and group dynamics (Barnes-Powell, 2008; Bennett, 2009; McArthur, 2007). This is especially significant with the alignment of group participant skills, roles and expectations, development of project management skills, budgeting skills, the ability to meet deadlines, modes of communication and presentation of and meeting the expectations of established industry professionals. On entering the workforce, they also have little personal experience of the benefits of team-based outcomes. Creative, IT and many other industry employer groups recognise this revolution in workplace focus. Many are increasingly specifying the need for interpersonal skills, particular behavioral characteristics and experience with group works, as key selection criteria for graduates, in some cases rating these over discipline-specific skills (Forde, 2000; Kennard, Willard \& Wilson, 2006; Treadwell \& Treadwell, 1999).

\section{The development of Creative Exchange}

Drawing on contemporary research that centres on the benefits of multidisciplinary collaboration (Bailey, 2010; Bennett, 2009; Meyer \& Staples, 1998; Rothstein, 2002), the Creative Exchange concept is a direct attempt to implement multidisciplinary practice within a tertiary learning environment. In the initial planning stages of the Creative Exchange, input was sought from the literature, academics from teaching and learning development, as well as creative arts lecturing staff and current students. A framework of key goals was developed.

The following points were highlighted in the early planning documents of Creative Exchange along with some of the underpinning global principles:

- Creative Exchange is based on building an interchange of ideas, to foster debate, to build bridges between individuals and between disciplines. 
- $\quad$ Creative Exchange is based on dialogue between students; between students and staff; and between students, staff and others from the university and the wider communitylocally, nationally and internationally.

- Creative Exchange supports discipline-specific expertise. However, Creative Exchange also recognises the potential interrelationship between all concepts, and will invite participation from other disciplines, cultures, the community and industry.

- $\quad$ Creative Exchange offers support to fledgling concepts, ignites and inspires both individual and team-driven directions and aspirations, and encourages students to speak out and build confidence in the articulation and expression of their ideas.

- Creative Exchange examines current debates and revels in contentious issues.

\section{Extending collaboration beyond the creative arts}

Considering the fast technological developments of the last two decades and how they have impacted on individuals living in post-industrial societies, it is clear that professions in the creative arts industry have considerably changed. New and specialised professions, such as web and multimedia designers, interface designers and digital copywriters have emerged. The cast of contributors to projects driven by technological innovation is extending in many cases beyond media and graphic design to include a diverse range of expertise such as information architecture, software engineering, research and theory, business strategy and content production - as well as digital photography, illustration, 3D model making, musical composition, performance and other allied creative disciplines. Hence as a result the initial scope of Creative Exchange has broadened from collaborative engagement within the creative arts to a broader rationale that includes noncreative arts' disciplines. This is especially the case for IT, but also for Business and Journalism.

Collaboration across departments and schools within a university environment can be difficult. Indeed, a recurring issue in the literature is the "silo" mentality of disciplines in universities that makes collaboration difficult (Design Skills Advisory Panel, 2007; Naylor, 2006; Vining, 2007). However, conducted research (Fleischmann, 2010; Szenasy, 2004) also confirmed that creative arts educators are generally enthusiastic about collaborative opportunities spanning diverse disciplines. A lack of sustainable solutions embracing the concept of multidisciplinary collaboration suggested to formalise an approach. Based on extensive research reported elsewhere (Fleischmann, 2010), the POOL MODEL framework (Fleischmann, 2008a, 2008b, 2010) that encapsulates the key goals of Creative Exchange and including non-creative arts disciplines was developed.

The POOL MODEL is a multidisciplinary system of interdependent collaborations with expertise exchange across university, industry and community sectors. In its core concept, the POOL MODEL provides a framework in which creative arts students are introduced to multidisciplinary collaborative learning with disciplines beyond the creative arts (e.g. IT). During this process, industry and community partners are encouraged to be an integral part of the undergraduate learning environment.

To provide for a flexible curriculum design, the core concept of the learning and teaching approach is based on a 'pool' idea (a group of resources or people to be 'used' when needed), a concept widely used to manage resources (e.g. a car pool). More recently, 'pools' have been used to facilitate innovation, for example, the ABC social media project "POOL" (ABC, 2009), which allows the audience to become "co-creators" through sharing creative work with the POOL community and $\mathrm{ABC}$ producers.

The pooling of people or expertise occurs in this research via a teaching and a learning pool 
containing specialists - students, educators, industry and community partners - from diverse but related disciplines. In each pool, multidisciplinary groups work together to either define a problem and guide the problem-solving process (teaching pool) or solve a problem (learning pool). Teams formed from both pools include members with expertise fundamental to solving the proposed problem or to guide the problem-solving process (Figure 1).

Creative Exchange was the first subject to be designed and trialed within the POOL MODEL framework in second semester of 2009.

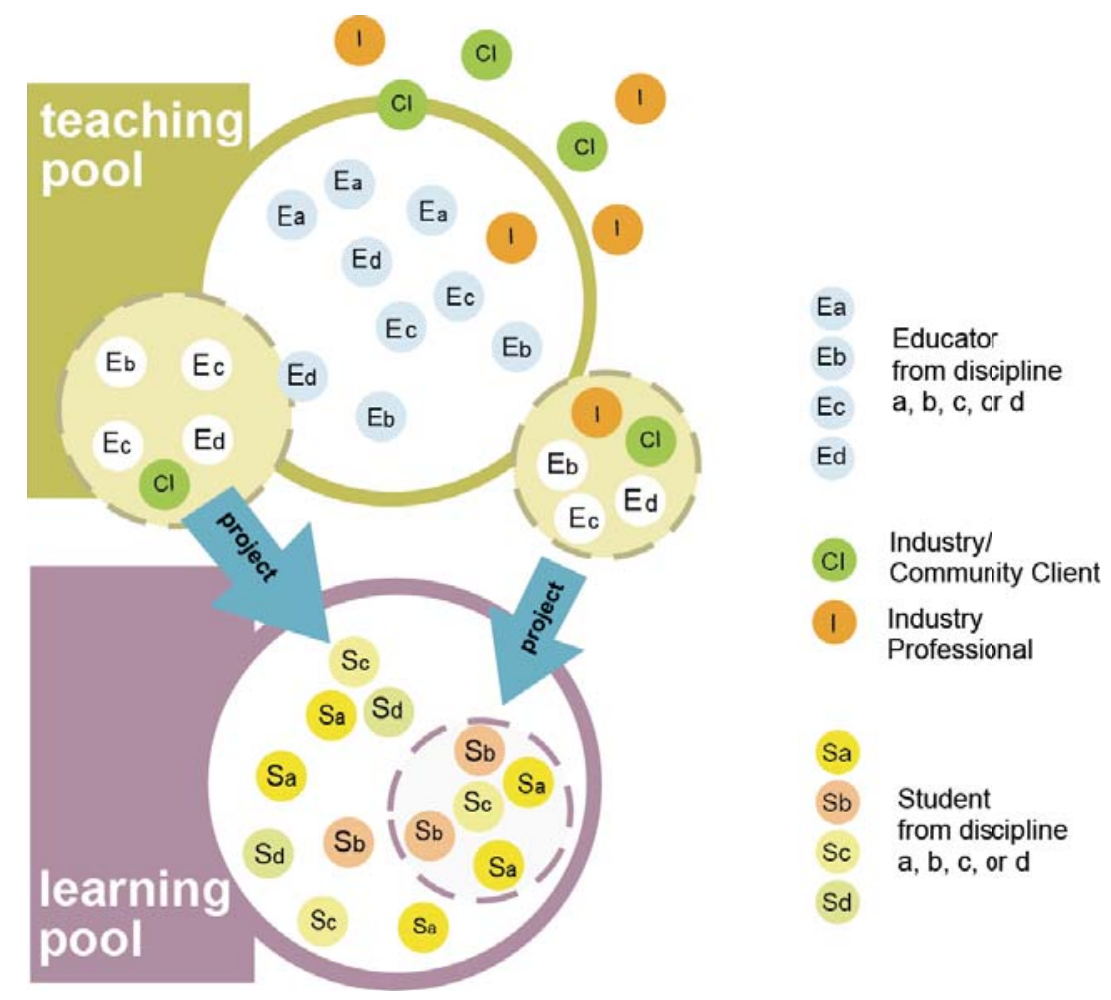

Figure 1. POOL MODEL: multidisciplinary learning and teaching in the creative arts and beyond

\section{Creative Exchange: Subject design}

In order to create a viable approach, the School of Creative Arts began developing and formalising collaborations with the School of Business, IT discipline, in 2007. During the development process, it was challenging to work within the existing curricula structure of both schools, for example, finding suitable subjects where learning outcomes can be aligned while ensuring that meaningful and industry-relevant opportunities are created for students from all participating disciplines. As a result, six disciplines were initially part of the learning pool in Creative Exchange: digital imaging, digital media design, digital visual arts, digital sound, performance and IT. 
In general, all students in the learning pool are in their final semester of their three-year bachelor degree and engage in a collaborative multidisciplinary team-based learning environment to directly experience the planning and production of a large-scale project during the thirteen-week semester. Each project may require diverse expertise input. Accordingly, students form teams choosing members from the learning pool with the discipline-specific skill sets necessary to produce the project. Each team is required to contain students from a minimum of three different disciplines. Projects may be either "real-world" in the sense of being provided by industry, community partners or directly assembled to emulate a typical industry project. Students are encouraged to seek alliances with participation from students of other schools within the university as well as within the community or industry.

Each team approaches their project within a project management framework. This process is managed separately through a team advisor. The team advisor (lecturing academic) monitors all teams, advising them on collaborative and project management practices. He/she also gives guidance for dysfunctional teams in order to resolve their problems. In addition, the team advisor monitors the development of a reflective process journal, which documents the development process and team experiences. The journal enables teams to reflect on the learning experience.

During the execution of the project, all teams have access to a wide range of creative arts and IT expertise from the teaching pool. Each team thus has two direct supervisors ensuring that students have access to discipline-specific expertise input which relates foremost to their project. For example, if a team develops an online shop, the supervising team would include expertise from the IT and digital media design area. In addition, all teams can access expertise input from all other lecturers from the learning pool when required. The overall subject and the inner- and interdepartmental collaboration is managed through two lecturers in the position of subject coordinators, who ensure that this complex process of expertise exchange and collaboration is an enriching experience for students as well as lecturers.

As industry and community partners are intended to be an integral part of the learning environment, various opportunities are made available for students to engage directly with the industry and the community. This can either occur through having industry or community input directly or by their involvement in the project through participating in the Creative Exchange meets Industry Day where students present a prototype of their project to industry professionals and seek their feedback.

\section{Creative Exchange: Implementation}

In 2009, a class of 45 new media arts students majoring in digital imaging, digital media design, digital sound, digital visual arts and performance and 22 IT students have been part of the learning pool. Thirteen student teams, with members from at least three different disciplines, have devised projects that intersect with new media, technology and the wider community. The team configurations were diverse in size and range of expertise. The largest team included three digital media design students, two visual arts students and four IT students. Some teams have formed alliances with students from journalism and business for the duration of the project.

Examples of projects range from the scripting and production of an interactive movie, to the design and development of an iPhone application, to a multi-player online game. Through the synthesis and conglomeration of participants' skills, each project provides the group with the opportunity to create an outcome of enduring worth that eclipses the potential of any one student. For example, for the development of the multi-player online game students formed a team including expertise from IT (two students), business (one student), digital sound (one student) and digital media design/visual arts (one student) simulating production teams in the real world (Figure 2). 
During the thirteen-week period, students developed their projects under supervision and input from eleven lecturers, with expertise in areas such as digital media design, art theory, digital sound, performance, digital imaging, film arts production, leadership and IT. The team that developed the multi-player online game for example, sought expertise input (advise, guidance, feedback) from educators from the area of digital media design, digital sound and IT and an IT industry professional during the project development (Figure 2).

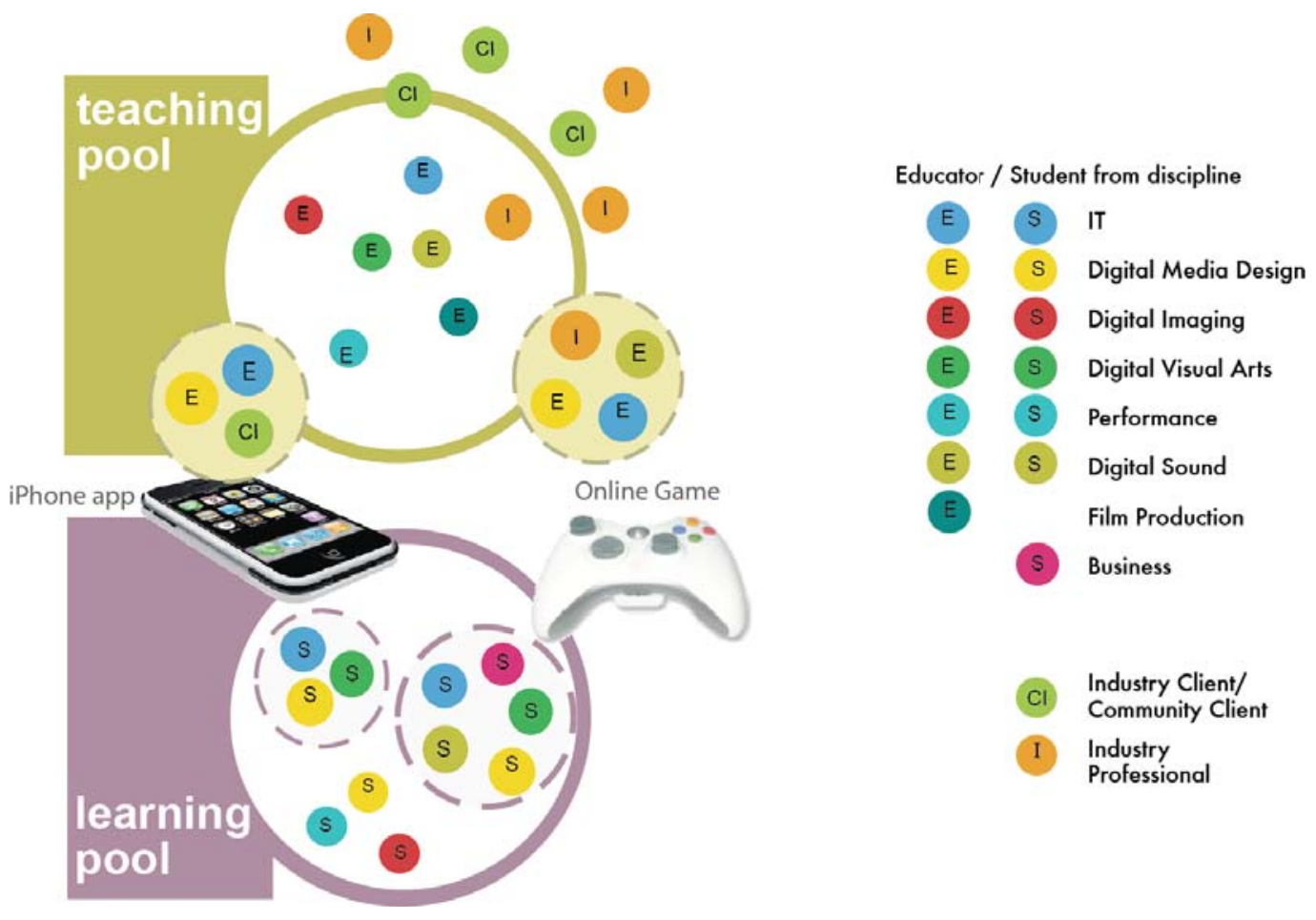

Figure 2. Learning and teaching POOL: examples of team constellation in Creative Exchange

Furthermore, students engaged in self-directed learning activities, pitched their concept idea to an external panel of lecturers and presented a project prototype to an industry panel consisting of four industry professionals from Germany, Melbourne and the region (Creative Exchange meets Industry Day). During this day, students sought real-world feedback on their projects. Special lecture content was delivered on topics such as how to prepare a pitch presentation and examples of best practice in multidisciplinary collaboration.

The project's results were presented in an all day Creative Exchange event at the end of the semester to lecturers, fellow students, industry and the wider community.

The participating students and lecturers were invited to provide feedback on their learning experiences through an anonymous online questionnaire. In addition, focus group interviews with student teams, lecturers, industry professionals and community partners were conducted to explore benefits and challenges of the Creative Exchange experience in more depth. The data presented in this paper represent the initial feedback provided by students on the concept of Creative Exchange. 


\section{Discussion}

In terms of multidisciplinary teamwork, all students who participated in the online survey $(n=31)$ thought that their project benefited from involving students from other disciplines. Students were especially excited about the concept of exchanging ideas with students from disciplines other than their own and the opportunity that afforded to create an outcome that eclipses the potential of any one student. When students were asked to identify the reasons for their positive view on multidisciplinary collaboration in the Creative Exchange from a given list (multiple answers possible), 27 students (82\%) liked that they could "bounce" ideas around with others, while 26 students (79\%) named the following three reasons equally often: (i) being exposed to multiple perspective (79\%); (ii) sharing the workload (79\%); and. (iii) creating something more complex $(79 \%)$.

In order to sustain the Creative Exchange, it is crucial to explore if links to other disciplines were considered beneficial and how the learning and teaching pool can be meaningfully expanded. Seeking students' feedback on their satisfaction-assuming the team configuration and sufficiency of skill sets are available within their teams for completing the project task-is an important step in exploring which disciplines might be added to the learning and teaching environment from the students' perspective. Hence, students were asked to comment on the sufficiency of expertise residing in their team for the successful development and completion of their envisioned project outcomes. Ten students $(30 \%)$ stated that they had all the necessary expertise in the team. Nearly half of the students $(49 \%)$ were confident that they had all the required expertise but were aware that it also required of them to learn and engage in something new in order to reach their goal. Seven students $(21 \%)$ felt that they would need additional expertise in order to complete the project successfully. Those students felt that, broadly, more expertise in IT and/or sound, especially game sound, music scoring based on visual media, and music mixing, was needed to complete the project. One team identified a person in their team with knowledge in the financial sector as a beneficial addition to their team, not only to have support in their endeavor to create a new fashion magazine for the region, but also to produce, publish and distribute it.

\section{Conclusion}

The Creative Exchange was the first subject in the School of Creative Arts that was designed and trialled based on the POOL MODEL, an alternative learning and teaching approach that embeds multidisciplinary collaboration in the creative arts and beyond, with industry and community partners being an integral part of the undergraduate learning environment.

Creative Exchange facilitates discipline-specific learning while simultaneously engaging students in multidisciplinary collaboration as part of the undergraduate curriculum. Teams of students learn to communicate ideas across disciplines, and to lead, manage and contribute effectively to their teams, thus developing an understanding of professional requirements in adjacent areas. As a result, students are arguably better prepared for their future collaborative multidisciplinary work environment in the creative industries.

Research is ongoing. However, initial feedback from students has been exceptionally positive to date and learning outcomes have been very pleasing. Presented data indicate a high level of student engagement and recognition of the benefits of the model for their future careers. Furthermore, first findings confirmed that opportunities for students to engage with a broad range of disciplines need to be extended. Hence, further collaborations are already formalised. For example, the School of Arts and Social Sciences, journalism discipline, became part of the learning and teaching pool in the Creative Exchange in 2011. 
Since its introduction in 2009, the Creative Exchange has become a capstone third-year subject within the Bachelor of New Media Arts and has recently been selected as model of best practice to be further developed into a capstone subject implemented across the Faculty of Law, Business and Creative Arts.

\section{References}

ABC. (2009). ABC POOL. Retrieved from http://pool.abc.net.au/

Ahmed, S., Camerano, C., Fortuna, L., Frasca, M., \& Jaccheri, L. (2009). Information technology and Art: Concepts and state of the practice. In B. Furht (Ed.), Handbook of Multimedia for Digital Entertainment and Arts (pp. 567-592). Berlin: Springer Verlag.

Bennett, R. (2009). Drawing on the virtual collective: Exploring online collaborative creativity. $\mathrm{PhD}$ thesis, University of Sydney.

Design Council and Creative \& Cultural Skill (2007). High-level skills for higher value. Report. Retrieved from http://www.designcouncil.org.uk/publications/high-level-skills-for-highervalue

DiPaola, S., Dorosh, D. \& Brandt, G. (2004). Ratava's line: Emergent learning and design using collaborative virtual worlds. ACM SIGGRAPH conference. Los Angeles, California. Retrieved from http://ivizlab.sfu.ca/media/ratava.pdf.

Ebert, D., \& Bailey, E. (1999). An interdisciplinary approach to teaching computer animation to artists and computer scientists. Retrieved from http://cobweb.ecn.purdue.edu/ ebertd/papers/GVE99final3.PDF

Fleischmann, K. (2008a). Facilitating sustainable partnerships between university, industry and the community within a new model for tertiary digital media design education. Paper presented at AUCEA NATIONAL CONFERENCE 2008. Sunshine Coast.

Fleischmann, K. (2008b). Overcoming disciplinary boundaries in undergraduate design education: Preparing digital media design students for collaborative multidisciplinary research practice. Paper presented at ACUADS conference, Australian Council of University Art and Design Schools. Adelaide, Australia.

Fleischmann, K. (2010). The POOL Model: Foregrounding an alternative learning and teaching approach for digital media design in higher education. Art, Design and Communication in Higher Education, 9(2), pp. 57-73.

Forde, P. (2000). Employer expectations for business graduate communication and thinking: An investigation conducted in Singapore and Perth. PhD Thesis. Curtin University of Technology.

Heller, S. (2005). What this country needs is a good five-year design program. In S. Heller (Ed.), The Education of a Graphic Designer (2nd ed., pp. 128-130). New York: Allworth Press.

Kennard, M., Willard, P., \& Wilson, C. (2006). What do they want? - A study of changing employer expectations of information professionals. Australian Academic and Research Libraries, 37(1), pp. 17-37.

McArthur, I. (2007). Learning continuums: Emerging paradigms reflections on the impact of graduate design education on professional design practice in the $21 \mathrm{stC}$. Visual: Design: Scholarship, 3(2), pp. 26-38.

Meyer, J., Staples, L., Minneman, S., Naimark, M. \& Glassner, A. (1998). Artists and Technologists working together (Panel) (pp. 67-69). UIST '98 - Proceedings of the 11th annual ACM symposium on User Interface Software and Technology, San Francisco, California, United States, ACM Press. 
Naylor, S. (2006). Moving the mind. Proceedings of the Australian Council of University Art and Designs Schools (ACUADS) Conference 2006, Monash University, School of Art, Victorian College of the Arts, Melbourne, Victoria.

Rothstein, P. (2002). When worlds collide: Integrated development with business and design students. Design Management Journal, 13(3), Summer, pp. 62-69.

Szenasy, S. (2004). School survey 2004 - Do America's design schools encourage interdisciplinary collaboration? Metropolis, August/September, pp. 88-91.

Treadwell, D., \& Treadwell, J. (1999). Employer expectations of newly-hired communication graduates. Journal of the Association for Communication Administration, 28(2), pp. 87-99.

Vining, P. (2007). Dr Frankenstein was a designer: Methods for educating Gen H-The hybrid design student. Master of Fine Arts thesis. Louisiana State University.

Copyright (C) 2012 Author(s) Katja Fleischmann \& Clive Hutchison 